\title{
Spectrum of Opportunistic Fungal Infections in HIV/AIDS Patients in Tertiary Care Hospital in India
}

\author{
Ravinder Kaur, ${ }^{1}$ Megh S. Dhakad, ${ }^{2}$ Ritu Goyal, ${ }^{2}$ Preena Bhalla, ${ }^{2}$ and Richa Dewan ${ }^{3}$ \\ ${ }^{1}$ Department of Microbiology, Lady Hardinge Medical College and Associated Hospitals, New Delhi 110001, India \\ ${ }^{2}$ Department of Microbiology, Maulana Azad Medical College and Associated Lok Nayak Hospitals, New Delhi 110002, India \\ ${ }^{3}$ Department of Medicine, Maulana Azad Medical College and Associated Lok Nayak Hospitals, New Delhi 110002, India
}

Correspondence should be addressed to Ravinder Kaur; rkaur.mamc@gmail.com

Received 2 February 2016; Revised 10 May 2016; Accepted 30 May 2016

Academic Editor: Maria L. Tornesello

Copyright (C) 2016 Ravinder Kaur et al. This is an open access article distributed under the Creative Commons Attribution License, which permits unrestricted use, distribution, and reproduction in any medium, provided the original work is properly cited.

\begin{abstract}
HIV related opportunistic fungal infections (OFIs) continue to cause morbidity and mortality in HIV infected patients. The objective for this prospective study is to elucidate the prevalence and spectrum of common OFIs in HIV/AIDS patients in north India. Relevant clinical samples were collected from symptomatic HIV positive patients $(n=280)$ of all age groups and both sexes and subjected to direct microscopy and fungal culture. Identification as well as speciation of the fungal isolates was done as per the standard recommended methods. CD4+T cell counts were determined by flow cytometry using Fluorescent Activated Cell Sorter Count system. 215 fungal isolates were isolated with the isolation rate of $41.1 \%$. Candida species (86.5\%) were the commonest followed by Aspergillus (6.5\%), Cryptococcus (3.3\%), Penicillium (1.9\%), and Alternaria and Rhodotorula spp. (0.9\% each). Among Candida species, Candida albicans (75.8\%) was the most prevalent species followed by C. tropicalis (9.7\%), C. krusei (6.4\%), C. glabrata (4.3\%), C. parapsilosis (2.7\%), and C. kefyr (1.1\%). Study demonstrates that the oropharyngeal candidiasis is the commonest among different OFIs and would help to increase the awareness of clinicians in diagnosis and early treatment of these infections helping in the proper management of the patients especially in resource limited countries like ours.
\end{abstract}

\section{Introduction}

The clinical profile of AIDS in India is seen to be different from what is seen in the developed world, since the HIV infected individual in India lives in an environment with high prevalence of infectious diseases [1]. The major causes of morbidity and mortality in HIV infected patients are the opportunistic infections (OIs). This could be attributed to the decreased level of immunity in such patients due to destruction of CD4+ cells. Thus, these patients become vulnerable to various OIs, particularly those caused by fungi $[2,3]$.

There are major differences in the spectrum of OIs in India and in the west $[1,4]$. Among the OFIs, Candida albicans, Cryptococcus neoformans, and Aspergillus fumigatus infections have accounted for most of the mycotic infections in immunocompromised individuals, and these infections often become life threatening [5-8]. Although Candida albicans have been found to be the most commonly isolated organism, some studies have shown that non-albicans Candida species including C. tropicalis, C. krusei, and C. glabrata are more prevalent than C. albicans [3].

The incidence of OFIs has increased, especially in hospitalised patients with the greatest risk [8] as in HIV infected patients. An early specific diagnosis and subsequent treatment to combat these infections are not only the concern of western hospitals but also equally relevant to developing countries like ours. In India, diagnosis as well as surveillance of these OFIs in AIDS is not easy, as there are not many laboratory setups presently to be able to deal with specific diagnosis of infection. In order to get an insight into the present scenario of the patients with HIV infection and AIDS in an Indian setup, the present study was planned to 


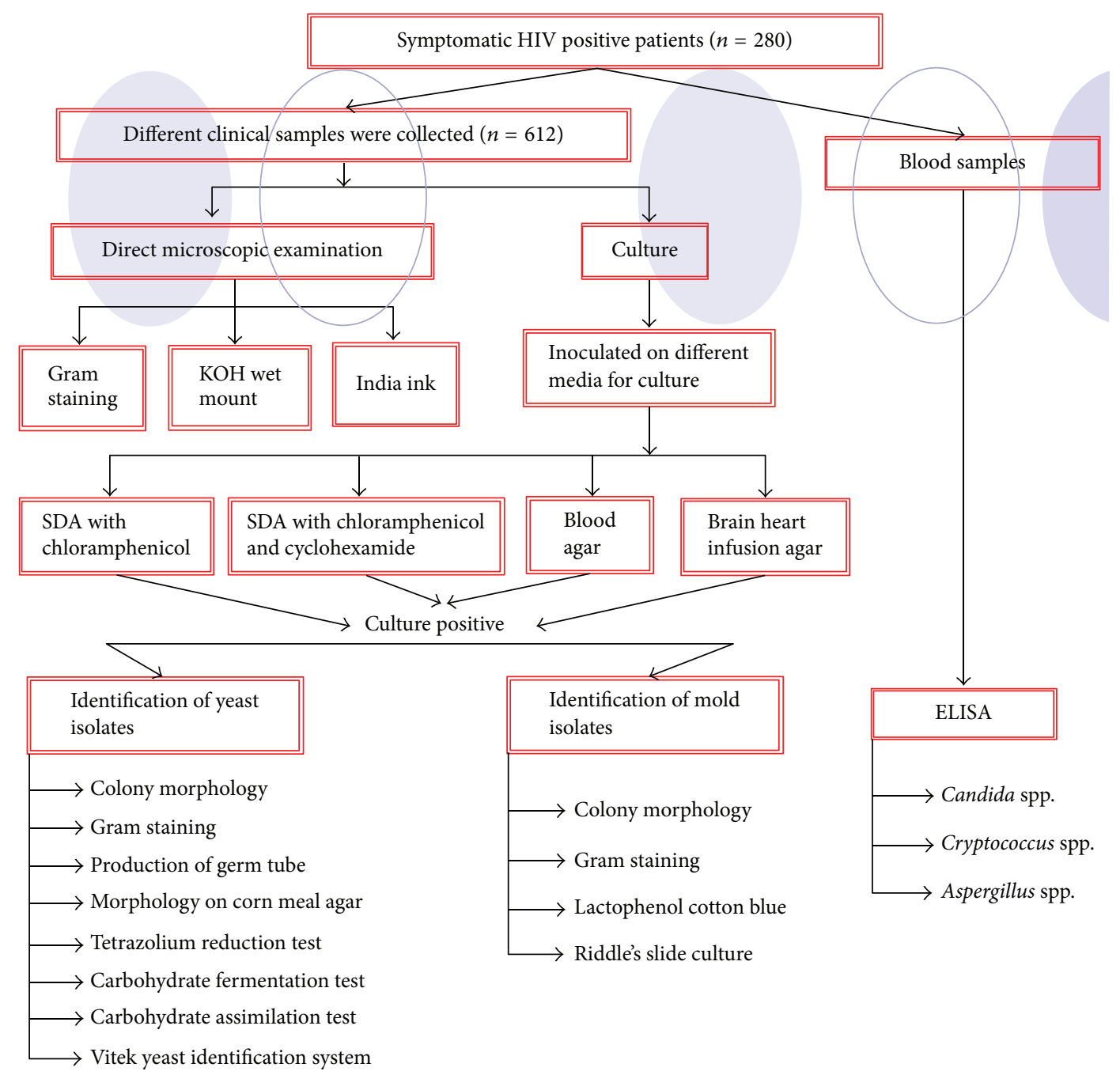

FIGURE 1: Flowchart of the study.

understand the prevalence and spectrum of common OFIs in HIV/AIDS patients.

\section{Material and Methods}

This study was approved by the institutional ethics committee, Maulana Azad Medical College and Associated Hospitals (Lok Nayak, GB Pant Hospital, Guru Nanak Eye Centre, and Chacha Nehru Bal Chikitsalaya), New Delhi, India. Individual informed consent was obtained from the patients.

2.1. Study Population and Design. Two hundred eighty patients $(n=280)$ of all age groups and both sexes attending outpatient departments (OPDs) or antiretroviral treatment clinic (ART clinic) or admitted in the medical wards of LNJP were studied. All patients were evaluated by a predesigned protocol covering the biodata, history including mode of transmission, presenting complaints, and physical examination. Figure 1 shows the flowchart of the study.
2.2. Microscopy, Culture, and Identification. Depending on the clinical symptoms and organ system involved, relevant clinical samples were collected with complete universal precautions. The samples were subjected to direct microscopy using Gram staining, $\mathrm{KOH}$ mounts, and India ink preparations, depending on the type of specimen and the suspected infection in the patient. Standard recommended procedures were used for diagnosis and isolation, which included a battery of tests $[14,15]$.

Fungal culture was done on Sabouraud dextrose agar with chloramphenicol $(16 \mathrm{mg} / \mathrm{mL})$ and with and without cycloheximide, blood agar, and brain heart infusion agar. Specimens were streaked in duplicate; one set of inoculated slants was incubated at $25^{\circ} \mathrm{C}$ and the other at $37^{\circ} \mathrm{C}$, and they were examined every other day for growth up to 4-6 weeks before discarding as negative. Samples inoculated on blood agar were incubated for $24-48 \mathrm{~h}$ and samples on brain heart infusion agar were incubated for 1-2 weeks $[14,16]$. Fungal growth was identified by colony morphology, Gram staining, lactophenol cotton blue preparation, and Riddle's 
TABLE 1: Age and sex distribution of the patients $(n=280)$.

\begin{tabular}{|c|c|c|c|c|c|c|c|c|}
\hline \multirow{2}{*}{ Age group (in years) } & \multicolumn{2}{|c|}{ Male } & \multicolumn{2}{|c|}{ Female } & \multicolumn{2}{|c|}{ Intersex } & \multicolumn{2}{|c|}{ Total } \\
\hline & $n$ & $\%$ & $n$ & $\%$ & $n$ & $\%$ & $n$ & $\%$ \\
\hline $0-10$ & 1 & 0.35 & 0 & 0 & 0 & 0 & 1 & 0.35 \\
\hline $11-20$ & 5 & 1.79 & 2 & 0.72 & 2 & 0.71 & 9 & 3.22 \\
\hline $21-30$ & 66 & 23.58 & 43 & 15.35 & 0 & 0 & 109 & 38.93 \\
\hline $31-40$ & 74 & 26.42 & 28 & 10.00 & 5 & 1.79 & 107 & 38.21 \\
\hline $41-50$ & 32 & 11.42 & 9 & 3.22 & 0 & 0 & 41 & 14.64 \\
\hline $51-60$ & 7 & 2.5 & 2 & 0.72 & 0 & 0 & 9 & 3.22 \\
\hline $61-70$ & 3 & 1.08 & 1 & 0.35 & 0 & 0 & 4 & 1.43 \\
\hline Total & 188 & 67.14 & 85 & 30.36 & 7 & 2.5 & 280 & 100 \\
\hline
\end{tabular}

slide culture as per standard recommended procedures [17]. Identification and speciation of yeast isolates were done on the basis of germ tube production, morphology on corn meal agar with Tween 80 (Hi Media), HiCrome candida agar (Hi Media), carbohydrate fermentation tests, assimilation tests using yeast nitrogen base agar (Hi Media) [14, 16, 17], and an automated Vitek-2 compact system (Biomérieux, India) as per standard recommended procedures.

2.3. Assessment of Immune Status. CD4 count was determined for each patient enrolled in our study by flow cytometry using the fluorescent activated cell sorter BD FACS Count system (Becton Dickinson) as per the manufacturer's instructions.

\section{Results}

Patients belonged to a wide age group (4-68 years). Maximum number of OFI cases was observed in $21-40$ years (77\%), the most productive age group of the country. We found that males $(67.14 \%)$ were more commonly infected, and a male predominance was seen in most of the age groups (Table 1).

Heterosexual mode of transmission was the commonest (71\%) route of HIV transmission. Clinically, patients presented with more than one symptom: the most common in our study population was weight loss $(78 \%)$, followed by oral ulcers $(75 \%)$, fever (67\%), headache (54\%), loss of appetite (44\%), cough (40\%), diarrhea (28\%), dyspnoea (27\%), neck rigidity (26\%), and others (4-19\%) (Table 2). AIDS defining illness like Tuberculosis was seen in $49.6 \%$ of patients followed by recurrent diarrhea $(28 \%)$ and recurrent herpes zoster (1.3\%). The gastrointestinal system was involved in all the patients, followed by the respiratory system (Table 2). Abdominal ultrasonographic study showed hepatosplenomegaly in $3.2 \%$ of patients and chest X-ray showed bilateral infiltrates in $5.4 \%$ of the patients.

The CD4 count ranged from 0 to 500 in $92 \%$ patients while only $8 \%$ had a count of $>500.133(47.5 \%)$ patients had CD 4 counts $<200$ cells $/ \mu \mathrm{L}$, while CD 4 count $<100$ cells $/ \mu \mathrm{L}$ was seen in $52(18.6 \%)$ and CD 4 count $<50$ cells $/ \mu \mathrm{L}$ in 25 (8.9\%) patients depicting a major population with severe immunosuppression (Figure 2).
TABLE 2: Frequency of clinical presentations and system involvement in patients.

\begin{tabular}{lcc}
\hline & Patient, $n$ & Patient, $\%$ \\
\hline Clinical presentations & 219 & 78.2 \\
Weight loss & 209 & 74.6 \\
Oral ulcer & 188 & 67.1 \\
Fever & 150 & 53.6 \\
Headache & 123 & 43.9 \\
Loss of appetite & 111 & 39.6 \\
Cough & 79 & 28.2 \\
Diarrhea & 75 & 26.8 \\
Dyspnea & 74 & 26.4 \\
Neck rigidity & & \\
Other (skin rash, night sweats, painful & 299 & $4-19$ \\
swallowing, loss of memory, & & \\
lymphadenopathy, sensory loss, burning & & \\
micturition, vision loss) & & \\
\hline System involvement & 280 & 100 \\
GI & 91 & 32.5 \\
Respiratory & 89 & 31.8 \\
Cardiovascular & 73 & 26.1 \\
CNS & 39 & 13.9 \\
Colorectal & 36 & 12.9 \\
Genitourinary & 4 & 1.4 \\
Skin & & \\
\hline
\end{tabular}

A total of 612 samples were collected and processed from 280 patients. Detailed distribution of different fungal isolates among various clinical samples is shown in Table 3. A total of 215 fungal isolates were isolated, Candida spp. (86.5\%) being the commonest followed by Aspergillus spp. (6.5\%), Cryptococcus spp. (3.3\%), Penicillium spp. (1.9\%), and Alternaria spp. and Rhodotorula spp. (0.9\% each).

Among the Candida isolates, C. albicans (141) was the most prevalent species followed by C. tropicalis (18), C. krusei (12), C. glabrata (8), C. parapsilosis (5), and C. kefyr (2). Among Aspergillus spp., A. niger (7) was the most common followed by A. fumigatus (5) and A. flavus (2). Among Cryptococcus spp., C. neoformans (5) was the most common followed 
TABLE 3: Distribution of different fungal isolates among various clinical samples.

\begin{tabular}{|c|c|c|c|c|c|}
\hline \multirow{2}{*}{ Clinical samples $(n=612)$} & \multicolumn{2}{|c|}{ Patients } & \multicolumn{3}{|c|}{ Fungal isolate distribution in clinical samples } \\
\hline & Patient, $n$ & Patient, \% & & Organism, $n$ & Organism, \% \\
\hline Oropharyngeal & 280 & 100 & Candida spp. & 138 & 49.3 \\
\hline \multirow{5}{*}{ Induced sputum } & \multirow{5}{*}{91} & \multirow{5}{*}{32.5} & Candida spp. & 30 & 33.0 \\
\hline & & & Aspergillus spp. & 12 & 13.2 \\
\hline & & & Penicillium spp. & 4 & 4.4 \\
\hline & & & Alternaria spp. & 2 & 2.2 \\
\hline & & & Cryptococcus spp. & 1 & 1.1 \\
\hline Blood & 89 & 31.8 & Candida spp. & 8 & 9.0 \\
\hline \multirow{2}{*}{ CSF } & \multirow{2}{*}{73} & \multirow{2}{*}{26.2} & Cryptococcus spp. & 6 & 8.2 \\
\hline & & & Candida spp. & 1 & 1.4 \\
\hline \multirow{2}{*}{ Stool } & \multirow{2}{*}{39} & \multirow{2}{*}{13.9} & Candida spp. & 3 & 7.7 \\
\hline & & & Rhodotorula spp. & 2 & 5.1 \\
\hline \multirow{2}{*}{ Urine } & \multirow{2}{*}{33} & \multirow{2}{*}{11.8} & Candida spp. & 5 & 15.2 \\
\hline & & & Aspergillus spp. & 2 & 6.1 \\
\hline Skin & 4 & 1.4 & No growth & - & - \\
\hline Genital sample & 3 & 1.1 & Candida spp. & 1 & 33.3 \\
\hline
\end{tabular}
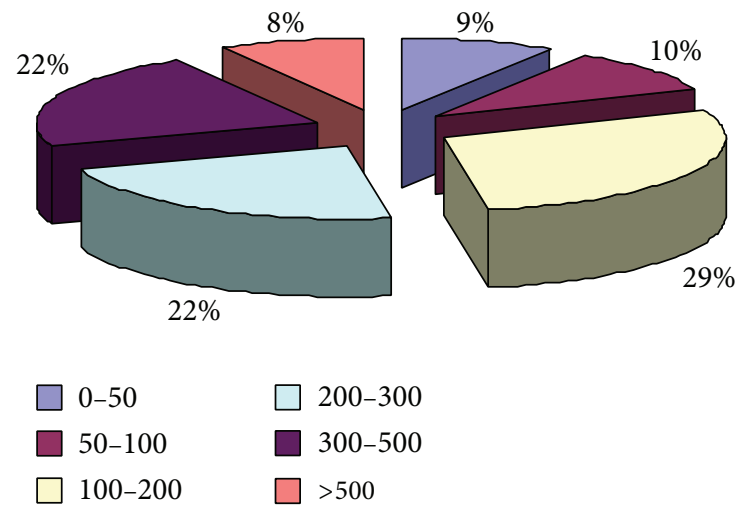

FIGURE 2: CD4 count profile of HIV/AIDS patients.

by C. gattii (2). However, 4 of Penicillium marneffei and 2 each of Alternaria alternata and Rhodotorula mucilaginosa were isolated (Table 4). Final diagnosis of infectious complications showed fungemia in $55(19.6 \%)$ cases followed by invasive candidiasis in $23(8.2 \%)$, invasive aspergillosis in $12(4.3 \%)$, and hepatosplenic candidosis in $9(3.2 \%)$ cases.

\section{Discussion}

HIV related OFIs are an important cause of morbidity and mortality in the developing nations like ours. There are many reports available regarding the pattern of OIs in HIV infected individuals [18], but the data from India on the etiology and spectrum of fungal infections of these patients are scarce [19]. Our study divulges the spectrum of common OFIs in HIV/AIDS patients in a tertiary care hospital in north India.

In this study, majority of the patients belonged to 21-40 years $(77 \%)$, the most productive age group of the country, showing a male preponderance with a male to female ratio of 2.25:1 consistent with studies on HIV patients in India
TABLE 4: Species distribution of different fungal isolates.

\begin{tabular}{lcc}
\hline Fungal isolates $(n=215)$ & $n$ & $\begin{array}{c}\% \text { of } \\
\text { total }\end{array}$ \\
\hline Candida spp. & 186 & 86.5 \\
C. albicans & 141 & 75.8 \\
C. tropicalis & 18 & 9.7 \\
C. krusei & 12 & 6.5 \\
C. glabrata & 8 & 4.3 \\
C. parapsilosis & 5 & 2.7 \\
C. kefyr & 2 & 1.1 \\
\hline Aspergillus spp. & 14 & 6.5 \\
A. niger & 7 & 50.0 \\
A. fumigatus & 5 & 35.7 \\
A. flavus & 2 & 14.3 \\
\hline Cryptococcus spp. & 7 & 3.3 \\
C. neoformans & 5 & 71.4 \\
C. gattii & 2 & 28.6 \\
\hline Penicillium marneffei & 4 & 1.9 \\
\hline Alternaria alternata & 2 & 0.9 \\
\hline Rhodotorula mucilaginosa & 2 & 0.9 \\
\hline
\end{tabular}

and Iran [20, 21]. Preponderance of males may be due to their migration to the metropolitan cities in search of work. Staying away from their spouse for longer periods and the philandering habit of males being seen might have resulted in their acquiring HIV infection. Moreover, the male preponderance seen might have been due to the fact that in the existing social milieu in India females do not seek medical care because of fearing ostracism and loss of family support $[22,23]$.

According to Joshi et al. (2004) [24] study, weight loss (58.8\%) was the most common clinical complaint, almost 
TABLE 5: Distribution of fungi in HIV positive patients.

\begin{tabular}{|c|c|c|c|c|c|c|}
\hline Reference number & Candida spp. & Aspergillus spp. & Cryptococcus spp. & Penicillium spp. & Alternaria spp. & Rhodotorula spp. \\
\hline [9] & $69.4 \%$ & $13.9 \%$ & $4.2 \%$ & - & - & - \\
\hline$[10]$ & $32.5 \%$ & $57.6 \%$ & $1.4 \%$ & - & - & - \\
\hline [11] & $18.3 \%$ & $6.9 \%$ & $0.6 \%$ & - & - & - \\
\hline$[12]$ & $55 \%$ & $3 \%$ & $4 \%$ & - & - & - \\
\hline [13] & $71.7 \%$ & $14 \%$ & $1.2 \%$ & $1.5 \%$ & - & $0.9 \%$ \\
\hline Our study & $86.5 \%$ & $6.5 \%$ & $3.3 \%$ & $1.9 \%$ & $0.9 \%$ & $0.9 \%$ \\
\hline
\end{tabular}

similar to our study. However, Gorantla et al. (2015) [25] observed fatigue and malaise (23\%) followed by fever $(16.8 \%)$, cough and dyspnoea (15.9\%), diarrhea (10.2\%), and weight loss $(9.3 \%)$ to be the major symptoms among the HIV seropositive patients.

In our study, Candida species (86.5\%) were the commonest followed by Aspergillus spp. (6.5\%) and Cryptococcus spp. $(3.3 \%)$ which is similar to the various studies as in Table 5 [9$13]$.

Among Candida species isolates, C. albicans (75.8\%) was the most prevalent species followed by C. tropicalis $(9.7 \%)$ almost similar to Gandham et al. (2013) [13] study from western part of India (2010 to 2012). However, in another study by Picardi et al. (2012) [26] in USA between 2004 and 2009 reported Candida non-albicans strains were more frequently isolated in neutropenic patients. Among Aspergillus spp., A. niger (50\%) was the most common followed by A. fumigatus (35.7\%) and A. flavus (14.3\%). However, Gandham et al. (2013) [13] reported $A$. fumigatus (53.2\%) to be the most common followed by A. niger (25.5\%) and A. flavus (14.9\%). Among Cryptococcus spp., C. neoformans (71.4\%) was followed by C. glutei $(28.6 \%)$ while in Gandham et al. (2013) [13] study only C. neoformans sp. (100\%) was isolated from the immunocompromised patients.

The findings of Xiao et al. (2013) [27] revealed the prevalence of Penicillium marneffei (1.4\%) to be almost similar to our findings (1.9\%). Penicilliosis is an important HIVassociated opportunistic infection known to be endemic in Southeast Asia [28]. In our study Alternaria alternata (0.9\%) were isolated in low frequency; a higher frequency $(5.6 \%)$ has been isolated in a study on cancer/HIV patients from central India [29]. All the isolates of Alternaria alternata were isolated from the respiratory samples of the patients, Alternaria alternata being thought to be the main airborne allergen of the genus Alternaria [30].

Rhodotorula species are generally considered to be nonpathogenic and have rarely been a cause of human infection [31]. In our study Rhodotorula species were isolated in low frequency, that is, $0.9 \%$, similar to a study from Brazil in 2010 [8]. However, ARTEMIS surveillance project reported that Rhodotorula species were the fourth most prevalent noncandidal yeast $(4.2 \%)$ isolated from clinical specimens [5].

In our study, Candida species was the most common isolate in oropharyngeal samples (49.3\%). Oropharyngeal candidiasis is the most common opportunistic fungal infection reported in many studies [3, 32-34]. The occurrence of oral candidiasis is recognized as an indicator of immune suppression and is often found in HIV infected patients with CD 4 counts fewer than 200 cells/ $\mu \mathrm{L}$ [27].

In sputum also Candida spp. (32.9\%) predominate followed by Aspergillus spp. (13.2\%); the relative proportions seen in this study reflect those seen by Bharathi and Rani, but absolute values are very different [35]. However, in blood Candida spp. are the fourth most common pathogen isolated from the blood of hospitalized patients [36]. In our study in blood, the prevalence of Candida infection (8.9\%) was higher, although a lot of variation in the prevalence and incidence of candidemia has been reported in different places in India varying from $1.6 \%$ to $6.9 \%$ [36-39].

In urine samples, Candida spp. (15.1\%) and Aspergillus spp. (6.1\%) were isolated in our study. A point prevalence survey done in 228 hospitals from 29 European countries determined that $9.4 \%$ of nosocomial UTIs were caused by Candida spp. Depending on the population examined, Candida is reported in up to $44 \%$ of urine samples sent for culture. Two retrospective analyses done in Israel and Italy found much lower rates (varying between 0 and 1.4\%) in urine cultures [40].

In stool samples, Candida spp. (7.6\%) and Rhodotorula spp. (5.1\%) were isolated in our study. However, Anwar Khan et al. (2012) [41] reported 5\% of patients had Candida diarrhea while Magalhães et al. (2015) [8] reported $0.9 \%$ Candida spp. isolation from stool samples of the hospitalized patients in Brazil in 2010. Rhodotorula spp. have been isolated from stool samples, indicating that these yeasts can survive in the extreme conditions of the gastrointestinal tract with recent studies having demonstrated an incidence of fungemia caused by Rhodotorula between $0.5 \%$ and $2.3 \%$ in the USA and Europe, respectively [42].

In CNS infections in our study, Cryptococcosis (8.2\%) was the most prevalent opportunistic fungal infection. However, Jain et al. [3], Chakraborty et al. [43], Sharma et al. [44], and Mulla et al. [34] reported a low incidence of Cryptococcosis $(6.7 \%, 4 \%, 3.7 \%$, and $2.9 \%$, resp.). Cryptococcosis is the most common systemic fungal infection among AIDS patients and its incidence is on the rise with the rapid spread of the disease $[3,45]$. CNS Cryptococcosis is one of the most important risk factors associated with HIV infection contributing to a very high degree of morbidity and mortality among HIV infected patients [3, 46].

For the prevention of OFIs, specific safety measures should be adopted such as good personal hygiene, early and 
regular medical examination, prompt diagnosis, and appropriate antifungal prophylaxis/treatment. These are necessary to decrease the morbidity and mortality associated with these infections in HIV infected patients, which in turn may increase their longevity [3].

Antifungal susceptibility testing plays an important role in managing and guiding therapeutic decision making especially for difficult to treat invasive candidiasis and aspergillosis. It also aids in drug development studies and as a means of tracking the development of antifungal resistance in epidemiological studies [45, 46].

In conclusion, oropharyngeal candidiasis was found to be most common OFIs with different fungal infections. This study would help to increase the awareness for clinicians to come up with right diagnosis and earlier treatment of these infections with the proper management of the patients especially in resource limited regions in India.

\section{Competing Interests}

No competing interests are declared.

\section{Authors' Contributions}

Ravinder Kaur and Megh S. Dhakad contributed equally.

\section{References}

[1] D. A. White and M. K. Zaman, "Medical management of AIDS patients," Medical Clinics of North America, vol. 76, no. 1, pp. 1944, 1992.

[2] J. D. Gradon, J. G. Timpone, and S. M. Schnittman, "Emergence of unusual opportunistic pathogens in AIDS: a review," Clinical Infectious Diseases, vol. 15, no. 1, pp. 134-157, 1992.

[3] S. Jain, A. K. Singh, R. P. Singh, J. K. Bajaj, and A. S. Damle, "Spectrum of opportunistic fungal infections in HIV-infected patients and their correlation with CD4+ counts in western India," Journal of Medical Microbiology and Infectious Diseases, vol. 2, no. 1, pp. 19-22, 2014.

[4] S. R. Aquinas, S. D. Tarey, G. D. Ravindran, D. Nagamani, and C. Ross, "Cryptococcal meningitis in AIDS-need for early diagnosis," Journal of Association of Physicians of India, vol. 44, no. 3, pp. 178-180, 1996.

[5] M. A. Pfaller, D. J. Diekema, G. W. Procop, and M. G. Rinaldi, "Multicenter comparison of the VITEK 2 antifungal susceptibility test with the CLSI broth microdilution reference method for testing amphotericin B, flucytosine, and voriconazole against Candida spp.," Journal of Clinical Microbiology, vol. 45, no. 11, pp. 3522-3528, 2007.

[6] P. C. N. Xavier, M. R. Chang, M. O. Nunes et al., "Neonatal candidemia in a public hospital in Mato Grosso do Sul," Revista da Sociedade Brasileira de Medicina Tropical, vol. 41, no. 5, pp. 459-463, 2008.

[7] J. Karkowska-Kuleta, M. Rapala-Kozik, and A. Kozik, "Fungi pathogenic to humans: Molecular bases of virulence of Candida albicans, Cryptococcus neoformans and Aspergillus fumigatus," Acta Biochimica Polonica, vol. 56, no. 2, pp. 211-224, 2009.

[8] Y. C. Magalhães, M. R. Q. Bomfim, L. C. Melônio et al., "Clinical significance of the isolation of Candida species from hospitalized patients," Brazilian Journal of Microbiology, vol. 46, no. 1, pp. 117-123, 2015.

[9] S. B. Jahromi and A. A. Khaksar, "Deep-seated fungal infections in immunocompromised patients in Iran," Iranian Journal of Allergy, Asthma and Immunology, vol. 4, no. 1, pp. 27-32, 2005.

[10] L. Pagano, M. Caira, A. Candoni et al., "The epidemiology of fungal infections in patients with hematologic malignancies: the SEIFEM-2004 study," Haematologica, vol. 91, no. 8, pp. 10681075, 2006.

[11] B. Kashyap, S. Das, I. R. Kaur et al., "Fungal profile of clinical specimens from a tertiary care hospital," Asian Pacific Journal of Tropical Biomedicine, vol. 2, no. 1, supplement, pp. S401-S405, 2012.

[12] R. Parmar, V. Sharma, C. Thakkar et al., "Prevalence of opportunistic fungal infections in HIV positive patients in tertiary care hospital in Rajkot," National Journal of Medical Research, vol. 2, no. 4, pp. 463-465, 2012.

[13] N. R. Gandham, S. V. Jadhav, M. Sardar, C. Vyawahare, and R. R. Misra, "The spectrum and aetiology of mycotic infections from a tertiary care hospital from western part of India," Journal of Clinical and Diagnostic Research, vol. 7, no. 10, pp. 2157-2159, 2013.

[14] B. A. Forbes, D. F. Sahm, and A. S. Weissfeld, "Laboratory methods in basic mycology," in Bailey and Scott's Diagnostic Microbiology, pp. 711-798, Mosby, St. Louis, Mo, USA, 11th edition, 2002.

[15] L. J. R. Milne, "Fungi," in Mackie and McCartney Practical Medical Microbiology, pp. 695-720, Churchill Livingstone, New York, NY, USA, 14th edition, 1996.

[16] E. W. Koneman, S. D. Allen, W. M. Janda et al., "Mycology," in Color Atlas and Textbook of Diagnostic Microbiology, pp. 9831057, Lippincott Williams and Wilkins, Philadelphia, Pa, USA, 5 th edition, 1997.

[17] G. S. Moore and D. M. Jaciow, Mycology for the Clinical Laboratory, Reston Publishing Company, Reston, Va, USA, 1979.

[18] P. R. Shahapur and R. C. Bidri, "Recent trends in the spectrum of opportunistic infections in human immunodeficiency virus infected individuals on antiretroviral therapy in South India," Journal of Natural Science, Biology and Medicine, vol. 5, no. 2, pp. 392-396, 2014.

[19] P. A. Khan, "Profile of fungal lower respiratory tract infections and CD4 counts in HIV positive patients," Virology \& Mycology, vol. 2, article 113, 2013.

[20] P. Badiee, A. Alborzi, M. A. Davarpanah, and E. Shakiba, "Distributions and antifungal susceptibility of Candida species from mucosal sites in HIV positive patients," Archives of Iranian Medicine, vol. 13, no. 4, pp. 282-287, 2010.

[21] S. Srirangaraj and D. Venkatesha, "Opportunistic infections in relation to antiretroviral status among AIDS patients from south India," Indian Journal of Medical Microbiology, vol. 29, no. 4, pp. 395-400, 2011.

[22] L. Tuli, A. K. Gulati, S. Sundar, and T. M. Mohapatra, "Correlation between CD4 counts of HIV patients and enteric protozoan in different seasons-an experience of a tertiary care hospital in Varanasi (India)," BMC Gastroenterology, vol. 8, article 36, 2008.

[23] A. K. Jha, B. Uppal, S. Chadha et al., "Clinical and microbiological profile of HIV/AIDS cases with Diarrhea in North India," Journal of Pathogens, vol. 2012, Article ID 971958, 7 pages, 2012.

[24] H. S. Joshi, R. Das, and A. K. Agnihotri, "Clinico-epidemiologicalprofile of HIV/AIDS patients in western Nepal a study 
from teaching hospital," Indian Journal of Preventive and Social Medicine, vol. 35, no. 1-2, pp. 69-76, 2004.

[25] M. Gorantla, K. Yadav, and V. M. Malhotra, "Spectrum of chief complaints and opportunistic infections among HIV seropositive patients attending a community care center in Nalgonda district, Andhra Pradesh," International Journal of Health Sciences and Research, vol. 5, no. 4, pp. 288-291, 2015.

[26] M. Picardi, S. Pagliuca, F. Chiurazzi et al., "Early ultrasonographic finding of septic thrombophlebitis is the main indicator of central venous catheter removal to reduce infection-related mortality in neutropenic patients with bloodstream infection," Annals of Oncology, vol. 23, no. 8, Article ID mdr588, pp. 21222128, 2012.

[27] J. Xiao, G. Gao, Y. Li et al., "Spectrums of opportunistic infections and malignancies in HIV-infected patients in tertiary care hospital, China," PLoS ONE, vol. 8, no. 10, Article ID e75915, 2013.

[28] T. Le, N. H. Chi, N. T. Kim Cuc et al., "AIDS-associated penicillium marneffei infection of the central nervous system," Clinical Infectious Diseases, vol. 51, no. 12, pp. 1458-1462, 2010.

[29] N. Warthe, S. M. Singh, S. R. Nawange, and S. Singh, "Spectrum of opportunistic fungal infections in Cancer/HIV patients: emerging fungal pathogens from Jabalpur Madhya Pradesh central India," Scholars Journal of Applied Medical Sciences, vol. 3, no. 3E, pp. 1385-1390, 2015.

[30] J. H. C. Woudenberg, N. A. van der Merwe, Ž. Jurjević, J. Z. Groenewald, and P. W. Crous, "Diversity and movement of indoor Alternaria alternata across the mainland USA," Fungal Genetics and Biology, vol. 81, pp. 62-72, 2015

[31] R. S. Shinde, B. G. Mantur, G. Patil, M. V. Parande, and A. M. Parande, "Meningitis due to Rhodotorula glutinis in an HIV infected patient," Indian Journal of Medical Microbiology, vol. 26, no. 4, pp. 375-377, 2008.

[32] T. K. Giri, I. Pande, N. M. Mishra, S. Kailash, S. S. Uppal, and A. Kumar, "Spectrum of clinical and laboratory characteristics of HIV infection in northern India," The Journal of Communicable Diseases, vol. 27, no. 3, pp. 131-141, 1995.

[33] A. Wadhwa, R. Kaur, S. K. Agarwal, S. Jain, and P. Bhalla, "AIDSrelated opportunistic mycoses seen in a tertiary care hospital in North India," Journal of Medical Microbiology, vol. 56, no. 8, pp. 1101-1106, 2007.

[34] S. A. Mulla, M. G. Patel, G. Vaghela, N. Motala, V. Desai, and R. Shrivastava, "A study of opportunistic infection in HIVseropositive patients," Indian Journal of Community Medicine, vol. 32, no. 3, pp. 208-209, 2007.

[35] M. Bharathi and A. U. Rani, "Pathogenic fungal isolates in sputum of HIV positive patients," Journal of AIDS and HIV Research, vol. 3, no. 6, pp. 107-113, 2011.

[36] S. C. Deorukhkar and S. Saini, "Species distribution and antifungal susceptibility profile of Candida species isolated from blood stream infections," Journal of Evolution of Medical and Dental Sciences, vol. 1, no. 3, pp. 241-249, 2012.

[37] A. K. Verma, K. N. Prasad, M. Singh, A. K. Dixit, and A. Ayyagari, "Candidaemia in patients of a tertiary health care hospital from north India," Indian Journal of Medical Research, vol. 117, pp. 122-128, 2003.

[38] I. Xess, N. Jain, F. Hasan, P. Mandal, and U. Banerjee, "Epidemiology of candidemia in a tertiary care centre of North India: 5year study," Infection, vol. 35, no. 4, pp. 256-259, 2007.

[39] V. Sahni, S. K. Agarwal, N. P. Singh et al., "Candidemia-an under-recognized nosocomial infection in Indian hospitals,"
Journal of Association of Physicians of India, vol. 53, pp. 607-611, 2005.

[40] J. M. Achkar and B. C. Fries, "Candida infections of the genitourinary tract," Clinical Microbiology Reviews, vol. 23, no. 2, pp. 253-273, 2010.

[41] P. Anwar Khan, A. Malik, and H. S. Khan, "Profile of candidiasis in HIV infected patients," Iranian Journal of Microbiology, vol. 4, no. 4, pp. 204-209, 2012.

[42] F. Wirth and L. Z. Goldani, "Epidemiology of rhodotorula: an emerging pathogen," Interdisciplinary Perspectives on Infectious Diseases, vol. 2012, Article ID 465717, 7 pages, 2012.

[43] N. Chakraborty, A. Mukherjee, S. Santra et al., "Current trends of opportunistic infections among HIV-seropositive patients from eastern India," Japanese Journal of Infectious Diseases, vol. 61, no. 1, pp. 49-53, 2008.

[44] S. K. Sharma, T. Kadhiravan, A. Banga, T. Goyal, I. Bhatia, and P. K. Saha, "Spectrum of clinical disease in a series of 135 hospitalised HIV-infected patients from north India," BMC Infectious Diseases, vol. 4, article 52, 2004.

[45] M. A. Pfaller and D. J. Diekema, "Progress in antifungal susceptibility testing of Candida spp. by use of clinical and laboratory standards institute broth microdilution methods, 2010 to 2012," Journal of Clinical Microbiology, vol. 50, no. 9, pp. 2846-2856, 2012.

[46] B. Posteraro, R. Torelli, E. De Carolis, P. Posteraro, and M. Sanguinetti, "Antifungal susceptibility testing: current role from the clinical laboratory perspective," Mediterranean Journal of Hematology and Infectious Diseases, vol. 6, no. 1, Article ID e2014030, 2014. 


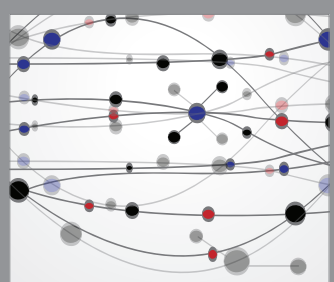

The Scientific World Journal
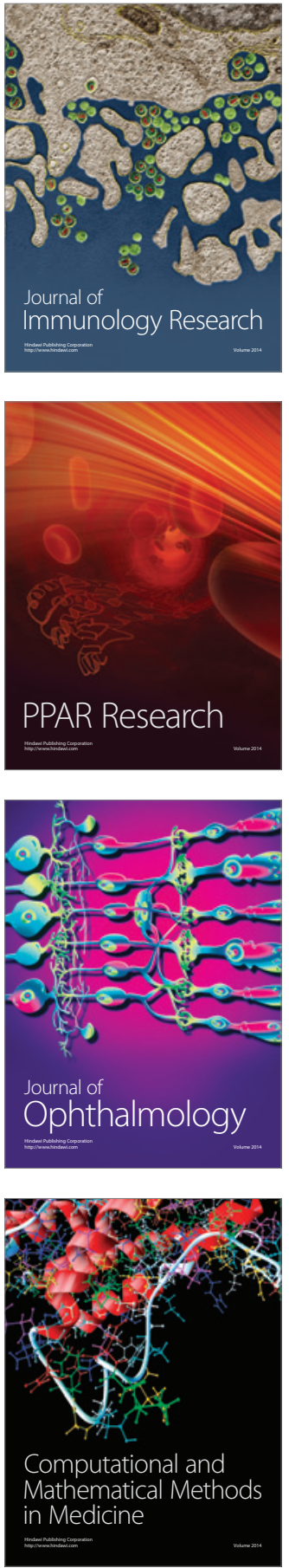

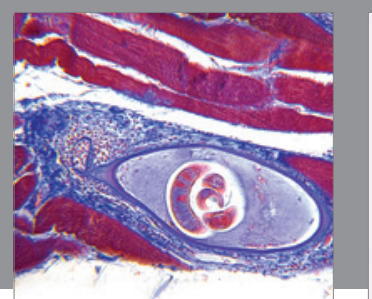

Gastroenterology Research and Practice

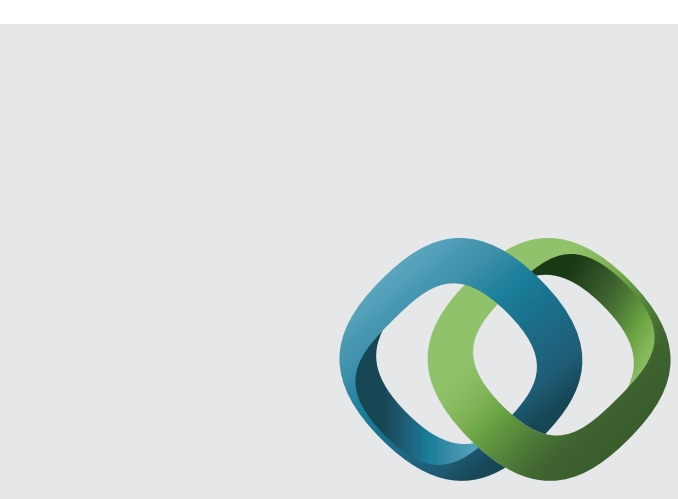

\section{Hindawi}

Submit your manuscripts at

http://www.hindawi.com
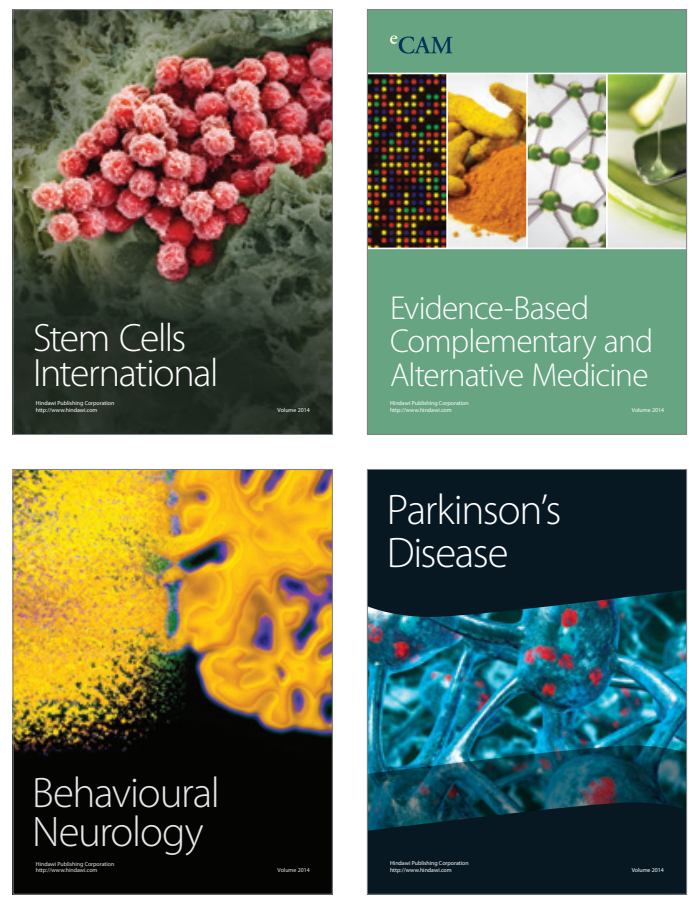
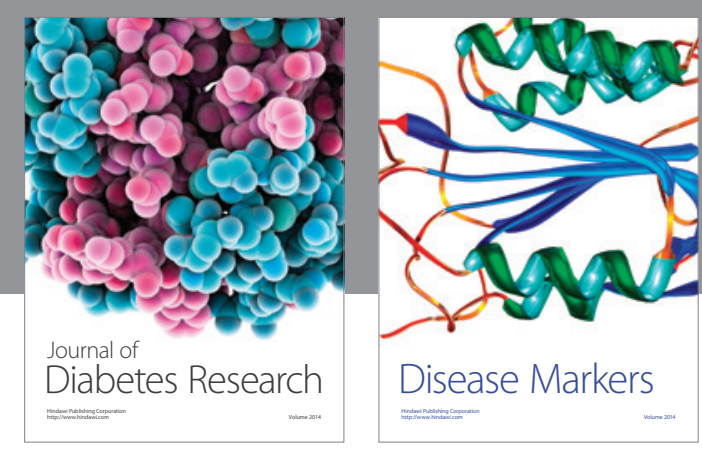

Disease Markers
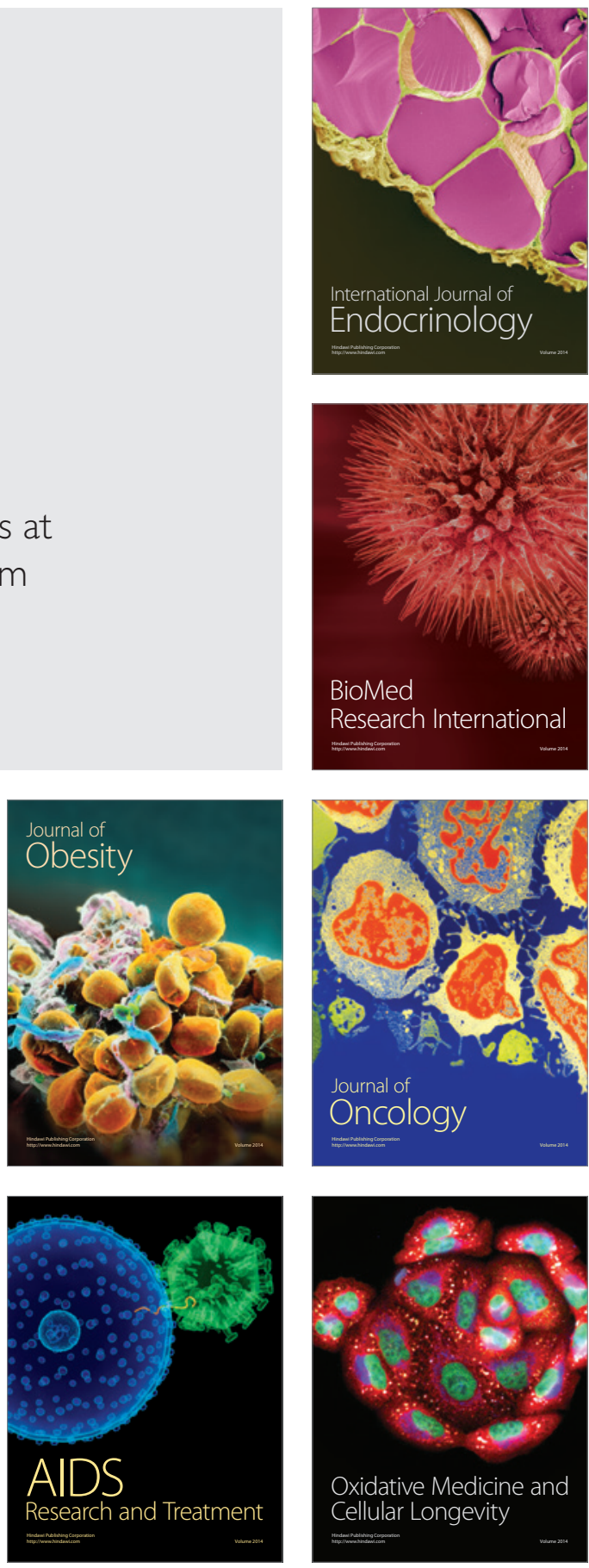